\title{
Enhancement of Performance for Steam Turbine in Thermal Power Plants Using Artificial Neural Network and Electric Circuit Design
}

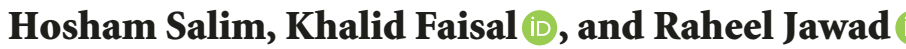 \\ Electro Mechanical. Eng. Dept., University of Technology, Baghdad, Iraq \\ Correspondence should be addressed to Raheel Jawad; raheeljawad2016@gmail.com
}

Received 12 May 2018; Revised 23 October 2018; Accepted 29 October 2018; Published 2 December 2018

Academic Editor: Shyi-Ming Chen

Copyright (C) 2018 Hosham Salim et al. This is an open access article distributed under the Creative Commons Attribution License, which permits unrestricted use, distribution, and reproduction in any medium, provided the original work is properly cited.

Design and implantation of electric circuit for enhanced performance of steam power plant and artificial neural networks technique are used to control turbine. Artificial neural networks technique is used to control a lot of industrial models practically. Artificial neural network has been applied to control the important variables of turbine in AL-Dura power plant in Baghdad such as pressure, temperature, speed, and humidity. In this study Simulink model was applied in MATLAB program (v 2014 a) by using artificial neural network (ANN). The method of controlling model is by using NARMA to generate data and train network. ANN is offline. ANN requires data to obtain results and for comparison with actual power plant. The values of the input variables have a large effect on the number of nodes and epochs and in hidden layer of the artificial neural network they also affect performance of ANN. The electric circuit of sensors consists of transformer, DC bridge, and voltage regulator. Comparing the results from modeling by ANN and electric circuit with experimental data reveals a good agreement and the maximum deviation between the experimental data and predicted results from ANN and circuit design is less than $1 \%$. The novelty in this paper is applying NARMA controller for the purpose of enhancement of turbine performance.

\section{Introduction}

A steam turbine of AL-Dura power plant of type (160MW) is used in this work, a steam turbine used to transfer heat energy in pressurized steam into useful mechanical work. The steam turbine consists of three sections, high, medium, and low pressure; first section is high pressure section that consists of two horizontally split casings; inner is placed inside and it is fixed in the axial directions, outer casing with scope for expansion in all directions. The second section is medium low pressure section that is split horizontally and comprises three parts connected by vertical flanges. The outlet branches are connected rigidly with condenser which is supported on springs. In the middle casing, tube nests of 1st and 2nd low pressure heaters are mounted. The casings are interconnected by guide keys and fixed points in the axial direction are at the central part of the low pressure casing [1]. In this study we offer the basic problem solutions and corrosion of steam turbine power plant. The chemical and mechanical properties of materials affect operating life of turbine blades. The stress corrosion and cracking of rotors and discs are major problems of steam turbine. In this study we discussed histories of repair welding of steam generator components with special emphasis on details of repair welding of cracked steam turbine blades [2]. In this study we calculated the stress and temperature using the finite element calculation program in cold condition and estimated the low cycle fatigue life loss using the general slope method and local stress and strain method steam turbine rotors of $1000 \mathrm{MW}$ ultra-supercritical [3]. In this study we use artificial neural networks to build a mathematical model of a steam turbine rotor by Nonlinear Auto-Regressive with exogenous inputs (NARX) to obtain the temperature and stress in critical rotor location online prediction of turbine. The measurements of power plant are a high pressure stage of turbine rotor, speed, load, temperature, and pressure of turbine before turbine control valve. We use the FE rotor model of trained neural networks which not only have 


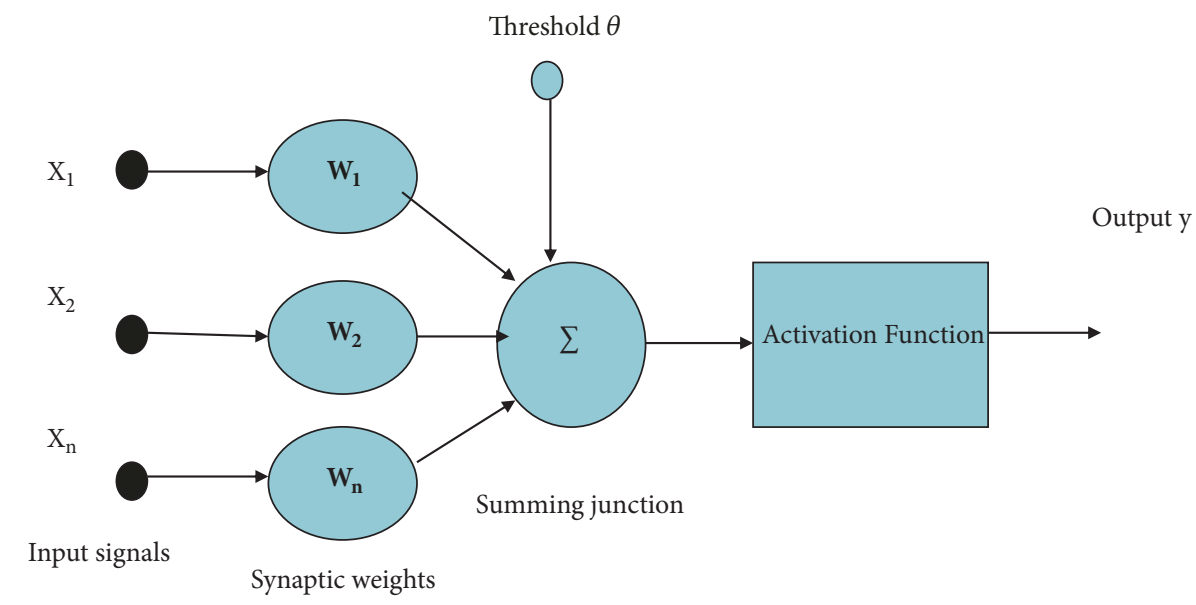

FIGURE 1: The elements of artificial neural network.

nonlinearity related to nonlinearity of expansion of steam turbine but also include FEM accuracy, nonlinearity during transient conditions inside the turbine as heat exchange, and rotor material properties. In turbine algorithms neural networks are used to be implemented as controllers. In industrial power plants neural networks are applied of steam turbine stress to control [4]. This study used an adaptive neurofuzzy inference system (ANFIS) modeling to predict turbine-generator output of turbine cycles for Unit 1 of the Kuosheng NPP in Taiwan. This plant operation information collected between 2006 and 2011 was verified using a linear regression model with a $95 \%$ confidence interval. The inputs for the ANFIS are throttle pressure, feed water flow rate, feed water temperature, and condenser pressure of turbine cycle model. The results show that the proposed ANFIS is capable of accurately and reliably demonstrating turbine cycle model to calculate turbine-generator output and compare these results with the thermodynamic turbine cycle model. The model was applied using the commercial software PEPSE. The neurofuzzy is effective and demonstrates turbine cycle model when using the actual operating data of Kuosheng NPP [5].

The aim of this article is improving the performance of the AL-Dura power plant by using artificial neural network (ANN) through controlling many parameters such as pressure, temperature, speed, and humidity.

\section{Artificial Neural Networks}

Artificial neural networks attempt to simulate some characteristics of the human nervous system. Neural networks origins go way back to the 1940s when Mc Culloch and Pitts built the first mathematical model of biological neurons. To create a model by neural networks is using analytical tools originally to cognitive function of the human brain. In its most general form, a neural network is a system or machine that is designed to model the way in which the brain performs a particular function; the artificial neural networks modeling is implemented by simulating in software on a digital computer. Artificial neural networks employ a massive interconnection of simple computing cells referred to as "neurons" to give a good performance. ANN is a system that performs a mapping between input and output patterns that represent a problem. The ANNs learn information during the training process after several iterations. When the learning process finishes, the ANN is ready to classify new information, predict new behavior, or estimate nonlinear function problems. Its structure consists of a set of neurons (represented by functions) connected among others organized in layers [6-9].

2.1. Basics of Artificial Neural Network (ANN). The ANN can be defined as a computing system which processes data by its dynamic state in response to external input. It is made up of a number of simple, highly interconnected processing elements. Figure 1 shows the elements of artificial neural network.

The type of network can be using feed forward in cascade to create a multilayer network. The output of a layer is the input to the following layer. An error signal can be employed by comparing the output values with the desired output value; this is called backpropagation, for adapting network weights. The backpropagation can be generalized for the input that is not included in the training patterns [10].

\section{Simulation of Steam Turbine Control System}

The steam turbine has been largely applied to power plant because of the costs efficiencies with respect to the capacity, application, and desired performance; a different level of complexity is offered for the structure of steam turbines, to increase the thermal efficiency so that the steam turbine consists of high pressure, intermediate pressure, and low pressure stages due to the complexity of turbine structure using artificial neural network to study the performance of steam turbine and more difficultly to predict the effects of proposed control system on the steam turbine in power plant, therefore, developing nonlinear analytical models. Design, synthesis, and performing real-time simulations and monitoring the 
desired state can be used, these models for control system in power plant [11-17]. A steam turbine of a 160MW power plant consists of steam extractions, feed water heaters, moisture separators, and the related motives. The turbine configuration and steam conditions at extractions. The important variables in this study that affect turbine in AL-Dura power plant such as temperature, pressure, speed, and humidity, by modeling, are simulated using MATLAB program (version 2014 a) according to structure control language that has been shown within the operating determination based on data obtained from the actual power plant.

\section{Input Variables of Artificial Neural Network (ANN)}

Variables that affect the operation of the power plant consist of the following.

(a) Temperature Input Variable. A safety operation of the steam turbine temperature to avoid damage in steam turbine blades in AL-Dura power plant, temperature generated from the turbine and entering into the turbine must be less than $550^{\circ} \mathrm{C}$.

(b) Pressure Input Variable. A safety operation of the steam turbine, pressure is less than 140 bar obtained from actual power plant.

(c) Speed Input Variable. The speed is an important variable that affects steam turbine in AL-Dura power plant because it affects the mechanical power that leads to improved efficiency; for the shaft of the turbine the speed must be more than 3500 r.p.m.

(d) Humidity Input Variable. The humidity is an important variable which endangers and affects the blade rotating inside the turbine. The value of the humidity should be less than 0.12; from experimental data the data range input and output parameters used for neural network training are shown in Table 1 . These data are divided as 50\% for training and 50\% for testing.

\section{Experimental Devices}

Experimental devices consist of interface part, personal computer, I/P user, and controller. This study includes two parts: hardware and software parts. The hardware part is for temperature, humidity, speed, and pressure sensors. The equivalent circuit of these signals is processed to be transferred to the interface unit. In interface unit the signals are processed to enter into the computer after which to take control an application that has been designed with the system requirements and consequently offers a message to the operator for you to make the right selection. Each sensor consists of electric transformer capable of increasing or decreasing the voltage and current levels of their supply, DC bridge which is used to convert signal to continuous voltage signal to obtain logic value of the signal represented by way of 1 and 0 , where one represents five volts and
TABLE 1: Input and output parameters of AL-Dura power plant.

\begin{tabular}{lcccc}
\hline $\mathrm{P}$ & $\mathrm{T}$ & $\mathrm{N}$ & $\mathrm{H}$ & output \\
\hline 40 & 270 & 2550 & 0.035 & 0 \\
45 & 285 & 2600 & 0.04 & 0 \\
50 & 300 & 2650 & 0.045 & 0 \\
55 & 315 & 2700 & 0.05 & 0 \\
60 & 330 & 2750 & 0.055 & 0 \\
65 & 345 & 2800 & 0.06 & 0 \\
70 & 360 & 2850 & 0.065 & 0 \\
75 & 375 & 2900 & 0.07 & 0 \\
80 & 390 & 2950 & 0.075 & 0 \\
85 & 405 & 3000 & 0.08 & 0 \\
90 & 420 & 3050 & 0.085 & 1 \\
95 & 435 & 3100 & 0.09 & 1 \\
100 & 450 & 3150 & 0.095 & 1 \\
105 & 465 & 3200 & 0.1 & 1 \\
110 & 480 & 3250 & 0.105 & 1 \\
115 & 495 & 3300 & 0.11 & 1 \\
120 & 510 & 3350 & 0.115 & 1 \\
125 & 525 & 3400 & 0.12 & 1 \\
130 & 540 & 3450 & 0.125 & 0 \\
135 & 555 & 3500 & 0.13 & 0 \\
\hline
\end{tabular}

zero represents zero volts. The continuous voltage signal is inserted to the voltage regulator type 7805 (5 volts or zero volts). Its function is to supply a stable voltage and its use as stabilizer may be restricted to ensuring that the output remains within certain limits. The analog signal converted to a digital signal when sensors read high. Figure 2 shows the diagram of sensing circuit and the photograph of sensing circuit. The software part consists of the flow chart and the algorithm written in MATLAB (2014a) program.

\section{Turbine Model Using Neural Network}

The type of controller of neural network used in this approach is the nonlinear autoregressive moving average (NARMA) which is designed and employed to control pressure, humidity, speed, and temperature of turbine. A demo model is provided with the Neural Network Toolbox to demonstrate the NARMA-L2 controller; the objective of NARMA is to control the position of a magnet suspended above an electromagnet, where the magnet is constrained so that it can only move in the vertical direction; NARMA is implemented in the ANN Tool-Box of simulation of MATLAB. In system identification of neural network model of the plant is developed. Controller block of NARMA is shown in Figure 3.

The block diagram of plant identification for the NARMA of turbine model works by adjusted parameters for generating data by insert, minimum and maximum values for the plant input and output, and minimum and maximum interval values as 0.1 seconds and 1 second. The size of the hidden layer, the number of delayed plant inputs and outputs, 
TABLE 2: Results of neural networks.

\begin{tabular}{lcccc}
\hline No of Nodes & Trained MSE & No of Nodes & Trained MSE & Test Regression \\
\hline 3 & $\mathbf{7 . 3 2 5 e - 0 6}$ & $3-5$ & $\mathbf{4 . 8 5 e - 0 6}$ & $\mathbf{2 0 3 e - 0 6}$ \\
5 & $\mathbf{2 . 9 6 6 e - 0 6}$ & $3-7$ & $\mathbf{1 . 9 5 e - 0 6}$ & $\mathbf{1}$ \\
9 & $\mathbf{9 . 1 9 5 e - 0 6}$ & $3-9$ & $\mathbf{8 . 6 0 9 e - 0 6}$ & $\mathbf{1}$ \\
11 & $\mathbf{8 . 1 6 4 e - 0 6}$ & $3-11$ & $\mathbf{1 . 6 6 7 e - 0 6}$ & $\mathbf{1}$ \\
14 & $\mathbf{9 . 9 6 2 e - 0 6}$ & $3-14$ & & $\mathbf{1}$ \\
\hline
\end{tabular}

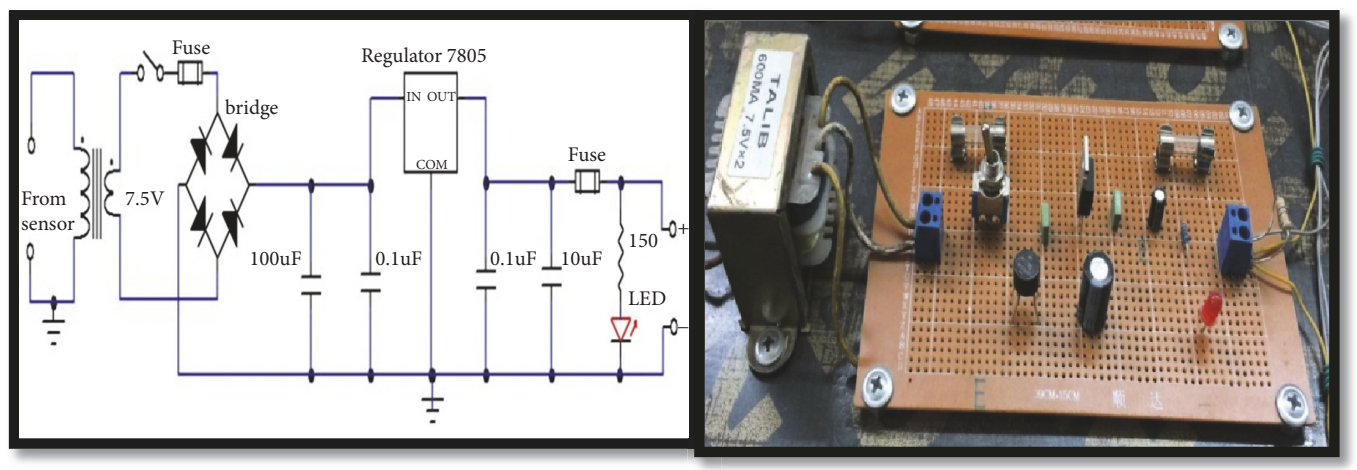

FIGURE 2: The diagram and photograph of sensing circuit.

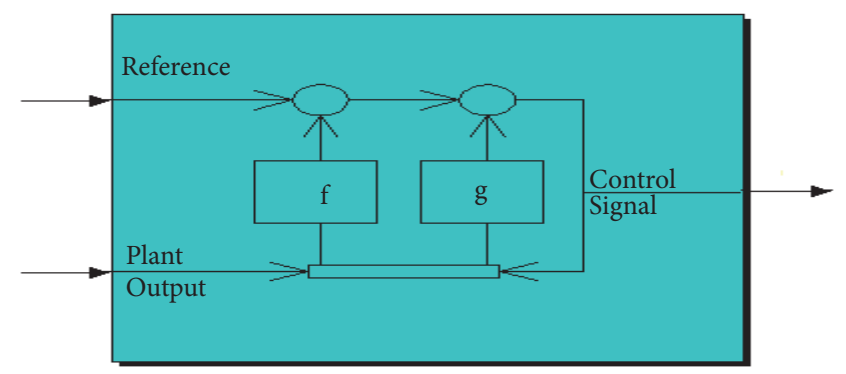

FIGURE 3: Controller block of NARMA.

the sampling interval, and finally the training function are trainlm. The training network then selected by the response of the resulting plant model was displayed. Separate plots for validation data, training data, and testing data are shown in Figures 4(a) and 4(b) illustrating flow chart of running NARMA.

\section{Result and Discussion}

Turbine model being developed in this study based on data from experimental setup to train and test neural network $\mathrm{NN}$ model based is simulated using MATLAB. To balance the training efficiency limited by number of neurons in the hidden layer through a trial and error NN training process and increase number of nodes in hidden layer is used to give good precision in network. Here, the neural network with two layers (hidden layer), 3-14 neurons, is studied and results of mean square error are listed in Table 2.

The objective of the training is to find an optimum answer of neural network. Figure 5 shows the best training performance that developed neural network with 2 hidden layers after 300 epochs. Figure 6 illustrates the good agreement between experimental data and NN predictions used for training. In the program we used two hidden layers, but each variable was controlled in NARMA using 14 hidden layers. This number of hidden layers gave the lowest error rate.

\section{Simulink Model of Steam Turbine of AL-Dura Power Plant}

The simulink model of turbine is designed to control of inputs variable (temperature, pressure, speed, and humidity) that affected steam turbine in AL-Dura power plant. Figure 7 shows the model of the steam turbine using NARMA. In this figure for control we suggest design and building of a model of ANN for each signal separately and then summing all signals in central process to reduce time that is used to take a decision. This suggested system represented a turbine of power plant of signals such as pressure, temperature, humidity, and speed. Processing all signals in one system takes a long time because this required repeating of weights of 

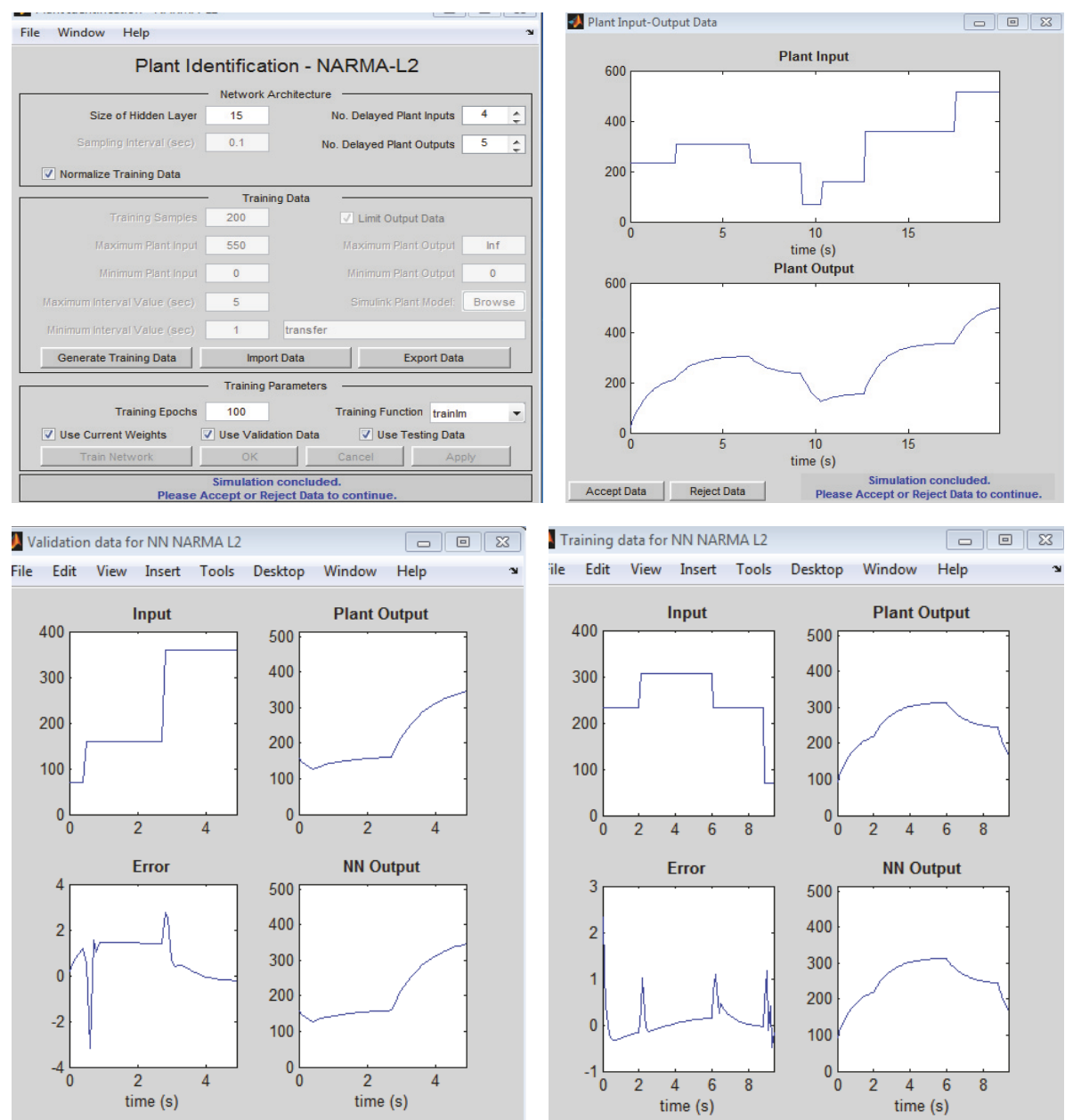

Testing data for NN NARMA L2
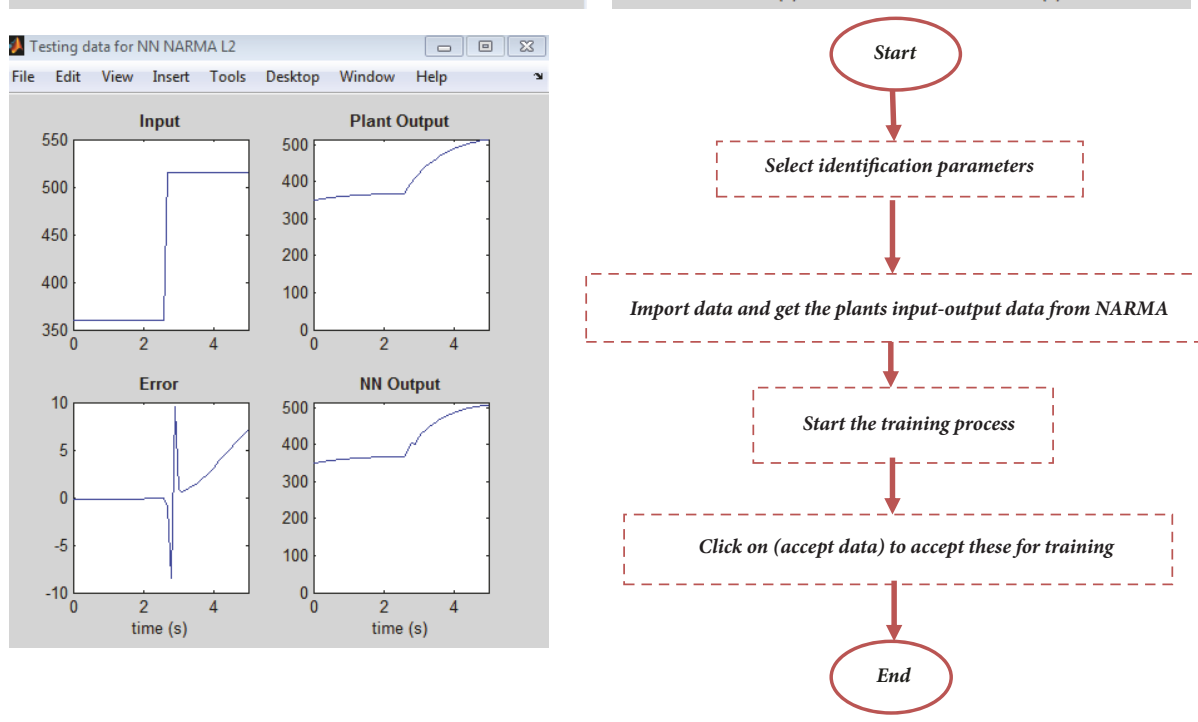

FIgURE 4: (a) The generated data of temperature and (b) flow chart of running NARMA.

ANN for all system and training and learning until reaching decision. So, this model works in steady state; when a problem or unexpected accident or change in one of signals takes place the problem is solved by ignoring this case, taking less process time, and all parts in system remain in steady state.

\section{Results of Model}

(1) Temperature. The temperature of turbine in power plant should be $550^{\circ} \mathrm{C}$ to keep blades of turbine and the turbine design to work in temperature from $520^{\circ} \mathrm{C}$ to $550^{\circ} \mathrm{C}$. Figure 8 shows input variable of temperature. 


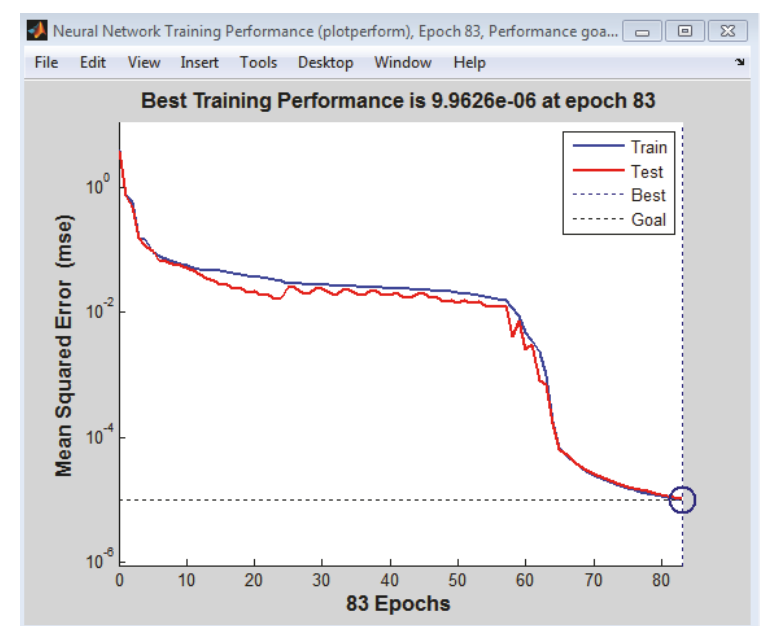

FIGURE 5: Best training performance.

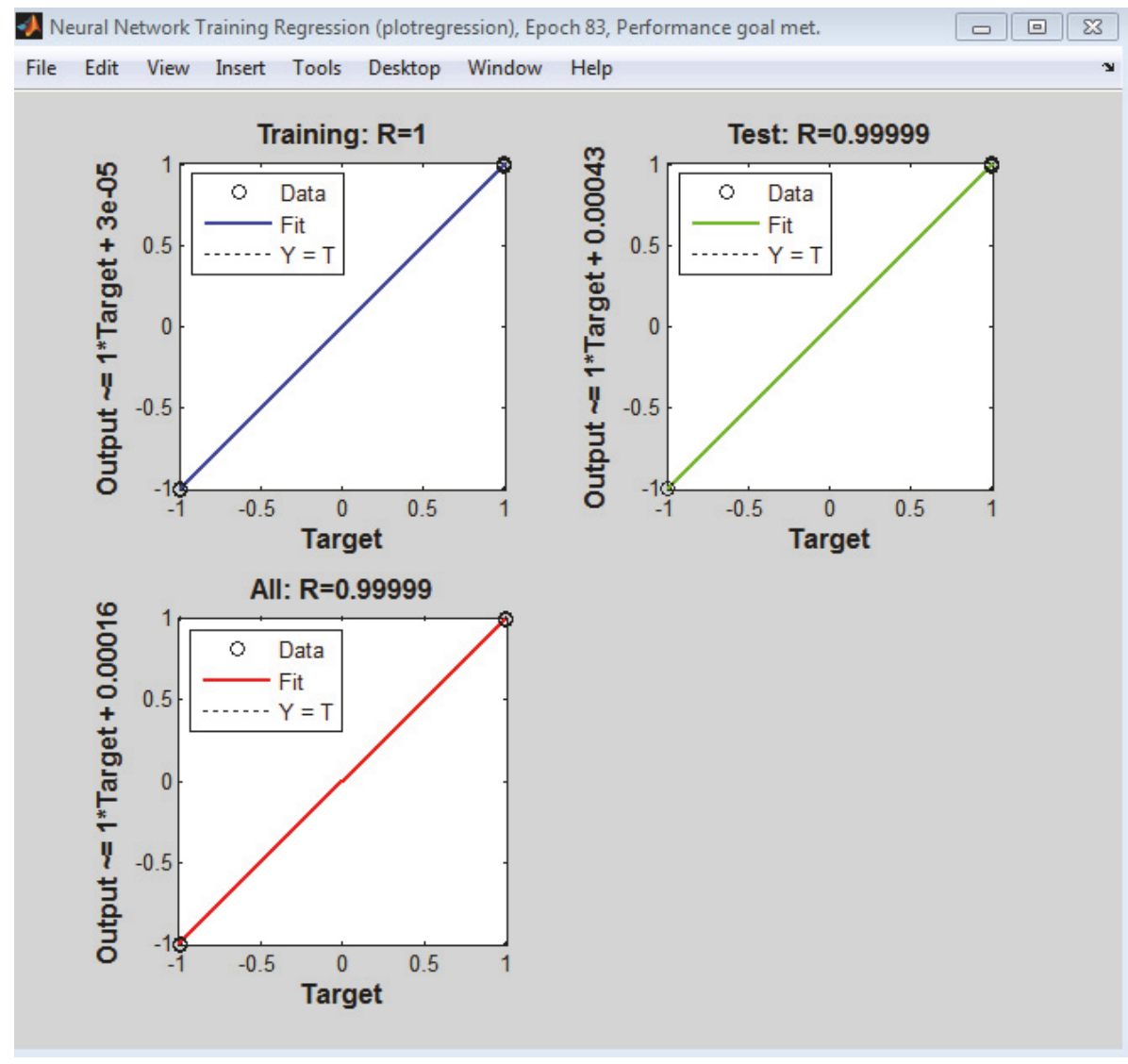

FIGURE 6: Desired and predicated output data for training neural network.

(2) Speed. The speed of turbine working in steady state is from 2500 to 3000 r.p.m. Figure 8 shows input variable of speed.

(3) Humidity. The humidity allowed to work in steam turbine in steady state is from 0 to 0.12 . Figure 8 shows input variable of humidity.

(4) Pressure. The pressure worked in all sections of turbine begins from 140 bar and then decreases to 6 bar entering into condenser. Figure 8 shows input variable of pressure of ALDura power plant.

\section{Results of Experimental Electrical Circuit}

Figure 9 shows practical pressure signal measured from experimental device. This signal explains the allowable limit for working a turbine at steady state. The pressure increases with increase in temperature. 


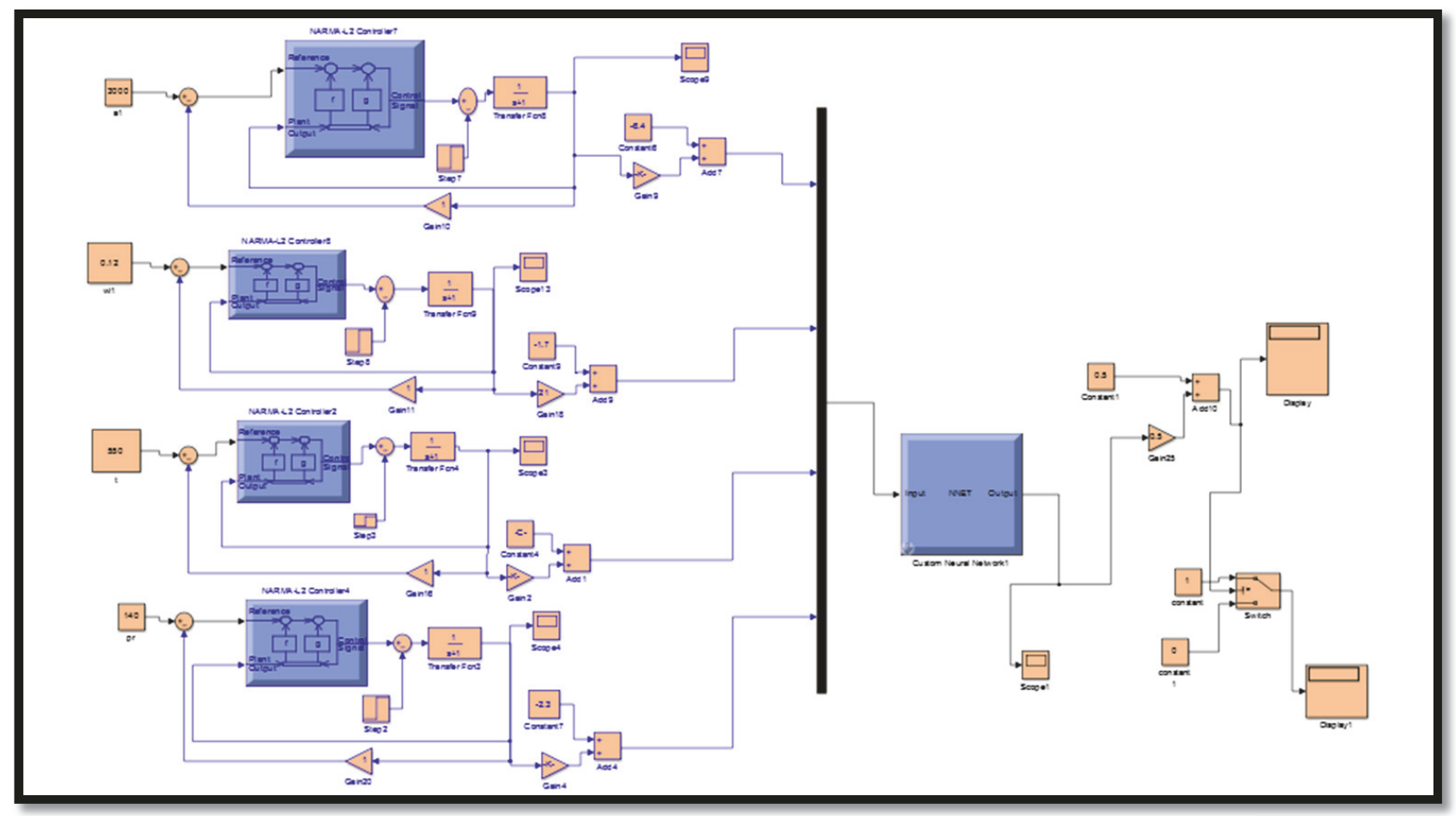

FIGURE 7: Simulink model of the steam turbine.
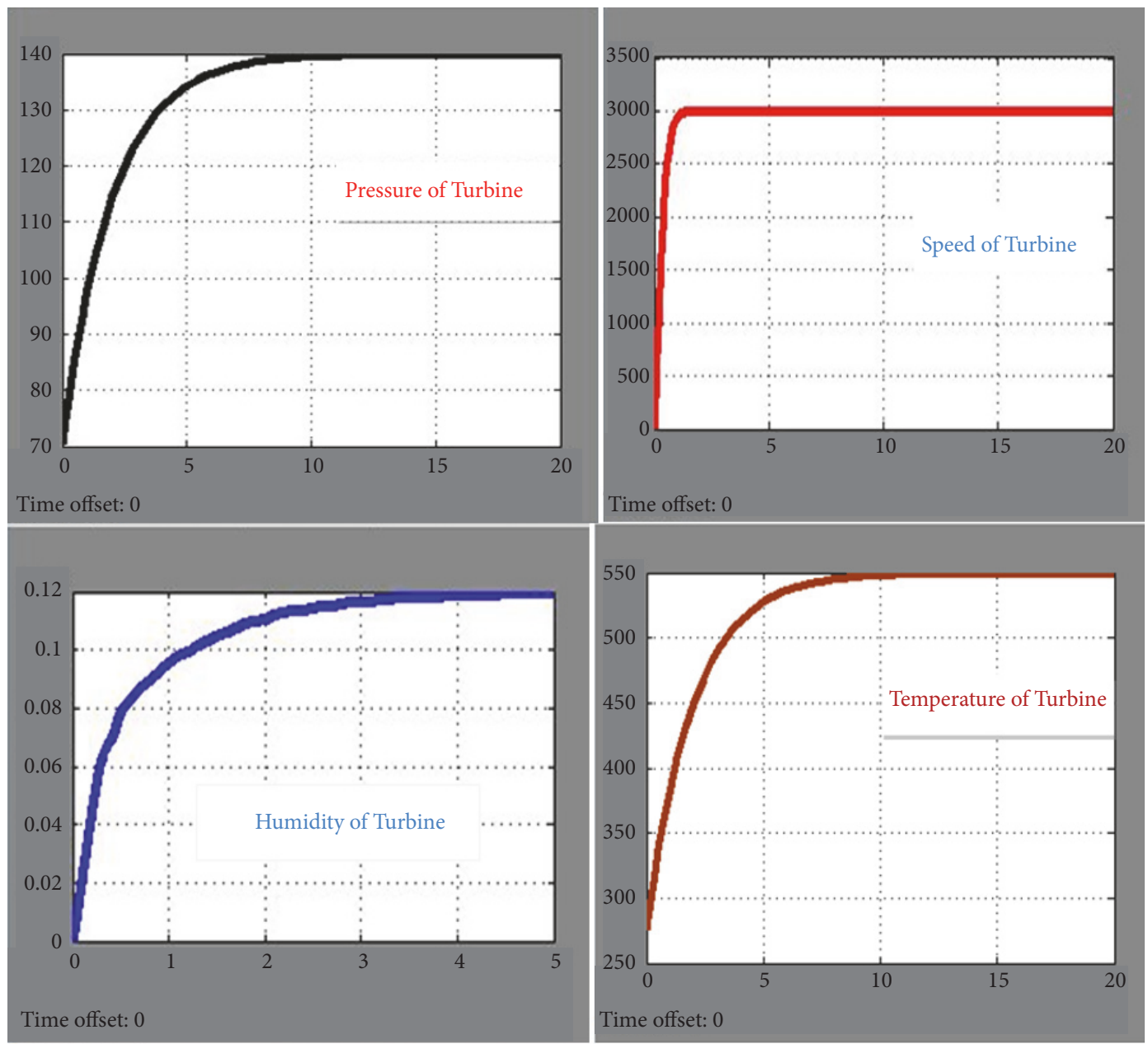

FIGURE 8: Input variables (pressure, humidity, temperature, and speed of AL-Dura power plant). 

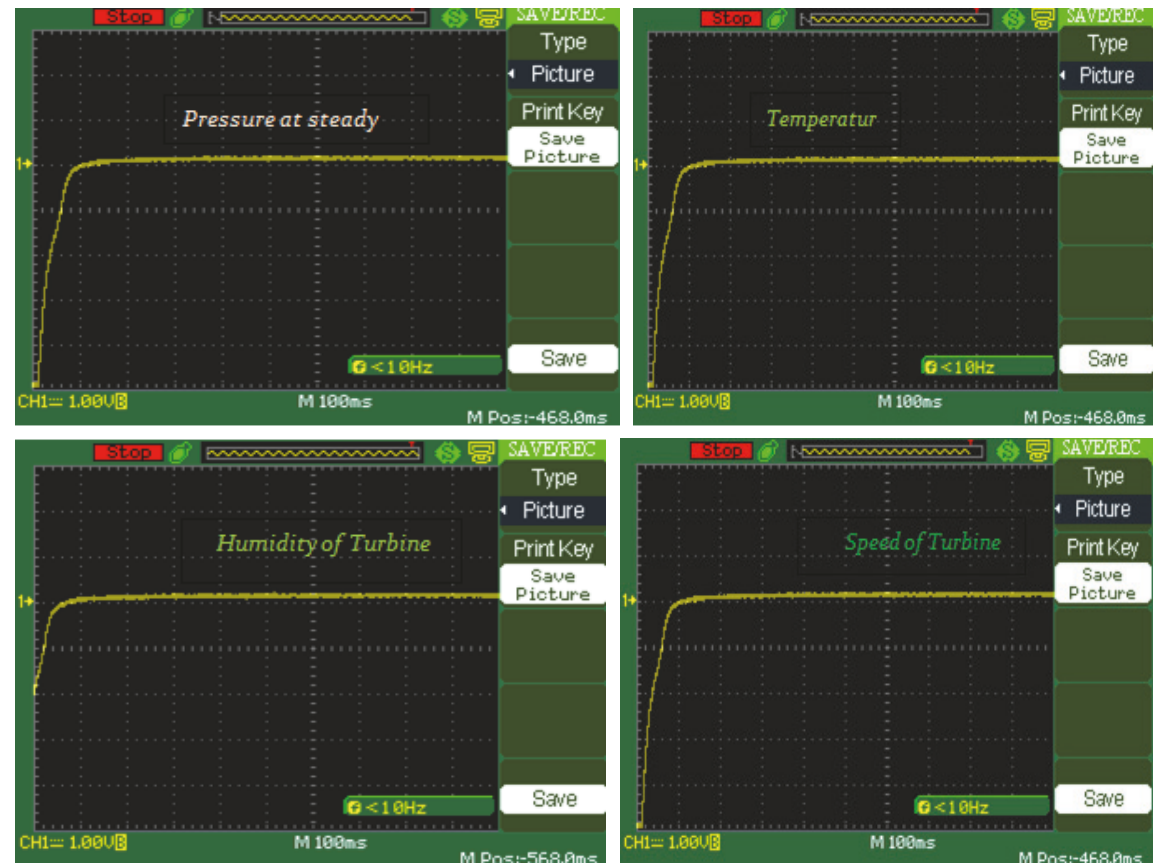

FIGURE 9: Pressure, temperature, humidity, and speed signals of turbine.

Also it shows practical temperature signal measured from experimental circuit and the allowed limit for the work of the turbine between 500 and $550^{\circ} \mathrm{C}$ as protection to the turbine from explosion and melting.

Also, humidity signal is taken from experimental device. The maximum limit allowed to work the turbine under normal condition is 0.12 . When temperature and pressure increase the humidity decreases and protects the blade of turbine from corrosion and erosion and shows practical speed signals taken from experimental device. The allowed limit to operate turbine in safety state is from 2500 r.p.m to 3000 r.p.m.

Figure 10 shows a comparison result humidity of turbine as an example between ANN and electric circuit design; the error between them is $1 \%$. When using electric circuit for control of plant, it gives a good result because this circuit is applied for real in Pepsi Baghdad company.

\section{Conclusion}

The application of the artificial neural network for the procedure control is one of the best methods for treating any complex problem by preparing sufficient training data and number of nodes to represent the internal features and relationships that connect input and output variables of automation engineer to construct the controller by himself based on his information and experience in the plant; the training of the artificial neural network depended on the values of the input variables that affected the number of epochs of the neural network as a result of the hyperbolic tangent function to reduce the training time by using maximum and minimum normalization method between the input and target values as compared with other normalization methods. The neural network is trained with the backpropagation

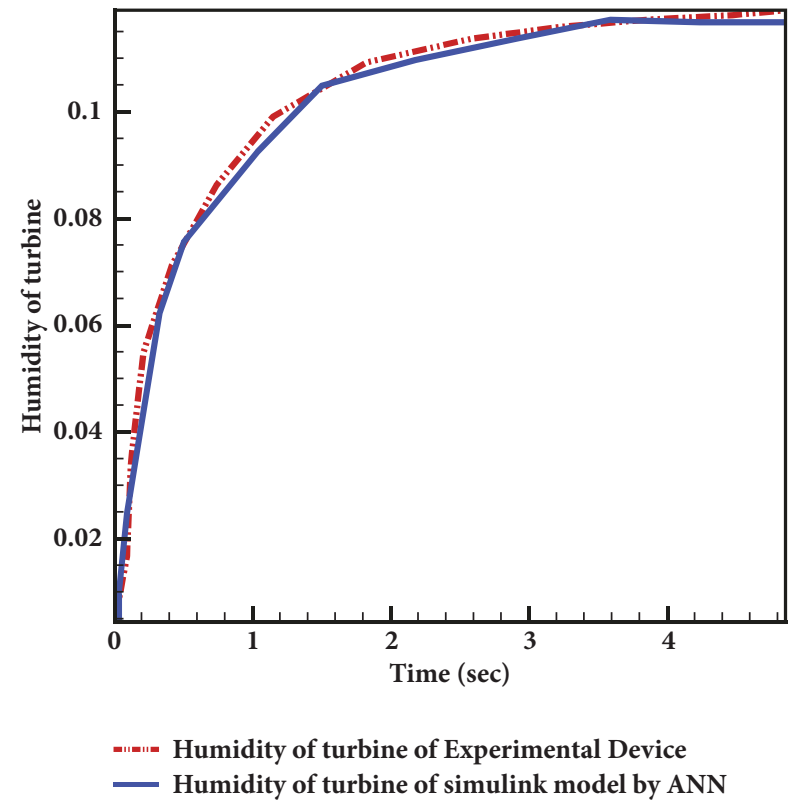

FIgURE 10: Comparison result humidity of turbine ANN and electric circuit design.

algorithm; this technique controls optimum values of real data taken from real plant (140 bar, 550C,0.12, 300 r.p.m.

\section{Nomenclature}

Variables

Wij: The weight in the connection

$\mathrm{X}$ : Input of neural network

Yj: The output for the computation unit. 


\section{Greek Symbols}

$\Theta$ : Threshold.

\section{Data Availability}

The data used to support the findings of this study are available from the corresponding author upon request.

\section{Conflicts of Interest}

The authors declare that they have no conflicts of interest.

\section{References}

[1] Amanraj, "Research Paper On Study Of Steam Turbine," International Journal of Innovative Research in Technology, vol. 2, no. 6, Article ID 142775, 2015.

[2] A. D. Kushwaha, A. Soni, and L. Garewal, "Critical Review Paper Of Steam Turbine Blades Corrosion And Its Solutions," International Journal of Scientific Research and Engineering Trends, vol. 3, no. 4, 2014.

[3] S. Bian and W. Li, "Calculation of Thermal Stress and Fatigue Life of 1000 MW Steam Turbine Rotor," International Journal of Energy and Power Engineering, vol. 05, no. 04, pp. 1484-1489, 2013.

[4] K. Dominiczak, R. Rzadkowski, and W. Radulski, "Steam turbine stress control using NARX neural network," Open Engineering, vol. 5, no. 1, pp. 421-428, 2015.

[5] Y.-K. Chan and J.-C. Gu, "Modeling of turbine cycles using a neuro-fuzzy based approach to predict turbine-generator output for nuclear power plants," Energies, vol. 5, no. 1, pp. 101118, 2012.

[6] P. Picton, Neural Network, Palgrave Macmillan, 2nd edition, 2000.

[7] D. Pallarès and F. Johnsson, "Macroscopic modelling of fluid dynamics in large-scale circulating fluidized beds," Progress in Energy and Combustion Science, vol. 32, no. 5-6, pp. 539-569, 2006.

[8] L. Duan, H. Sun, C. Zhao, W. Zhou, and X. Chen, "Coal combustion characteristics on an oxy-fuel circulating fluidized bed combustor with warm flue gas recycle," Fuel, vol. 127, pp. 47-51, 2014.

[9] U. Kesgin, "Genetic algorithm and artificial neural network for engine optimisation of efficiency and NOx emission," Fuel, vol. 83, no. 7-8, pp. 885-895, 2004.

[10] J. M. Zurada, Introduction To Artificial Neural Systems, JAICO publishing house West, 1992.

[11] W.-C. Tsai, T.-P. Tsao, and C. Chyn, "A nonlinear model for the analysis of the turbine-generator vibrations including the design of a flywheel damper," International Journal of Electrical Power \& Energy Systems, vol. 19, no. 7, pp. 469-479, 1997.

[12] J. Krzywanski, W. Nowak, and J. Krzywański, "Neurocomputing approach for the prediction of NOx emissions from CFBC in air-fired and oxygen-enriched atmospheres," Journal of Power Technologies, vol. 97, no. 2, pp. 75-84, 2017.

[13] J. Krzywanski, H. Fan, Y. Feng, A. R. Shaikh, M. Fang, and Q. Wang, "Genetic algorithms and neural networks in optimization of sorbent enhanced $\mathrm{H} 2$ production in $\mathrm{FB}$ and CFB gasifiers," Energy Conversion and Management, vol. 171, pp. 1651-1661, 2018.
[14] Z. N. S. Vanini, K. Khorasani, and N. Meskin, "Fault detection and isolation of a dual spool gas turbine engine using dynamic neural networks and multiple model approach," Information Sciences, vol. 259, pp. 234-251, 2014.

[15] S. Hosham, F. Anead Khalid, and J. Raheel, "Evaluation and Improvement Performance of a Boiler in a Thermal Power Plant Using Artificial Neural Network," Engineering \& Technology Journal, vol. 36, Part A, no. 6, 2018.

[16] Z. N. Sadough Vanini, N. Meskin, and K. Khorasani, "Multiplemodel sensor and components fault diagnosis in gas turbine engines using autoassociative neural networks," Journal of Engineering for Gas Turbines and Power, vol. 136, no. 9, 2014.

[17] S. S. Tayarani-Bathaie, Z. N. Sadough Vanini, and K. Khorasani, "Fault detection of gas turbine engines using dynamic neural networks," in Proceedings of the 2012 25th IEEE Canadian Conference on Electrical and Computer Engineering, CCECE 2012, Canada, May 2012. 


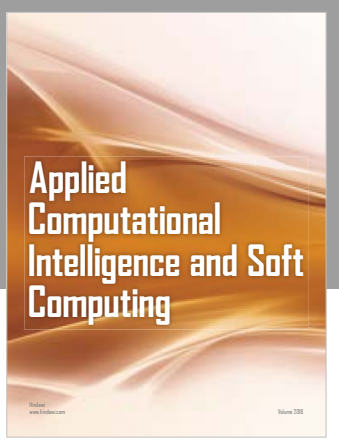

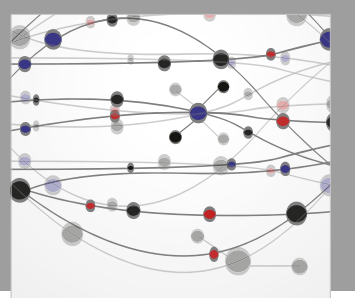

The Scientific World Journal
Submit your manuscripts at

Computing
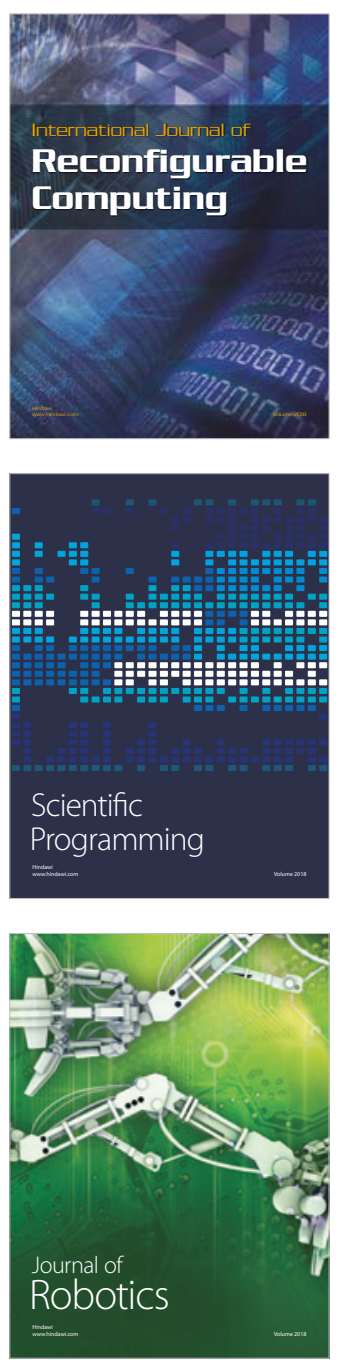

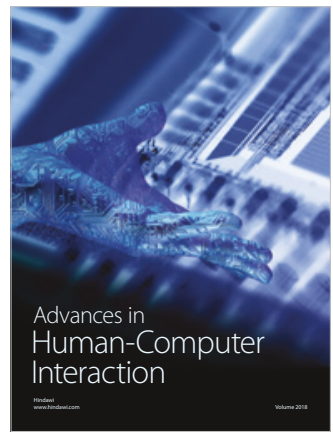

Human-Compute

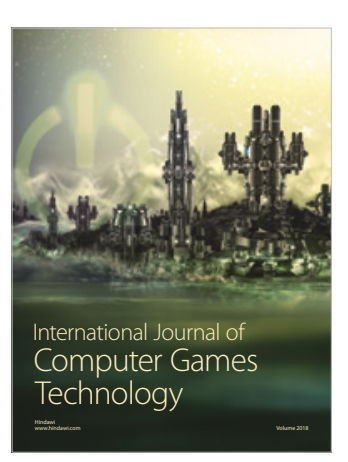

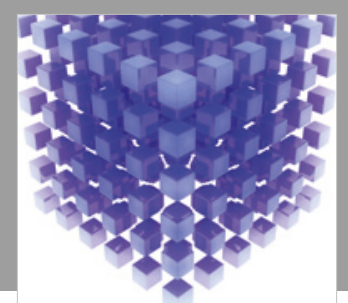

Mathematical Problems in Engineering

\section{Engincering}
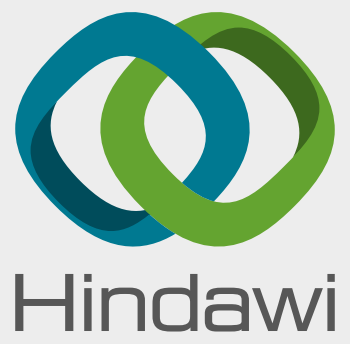

www.hindawi.com
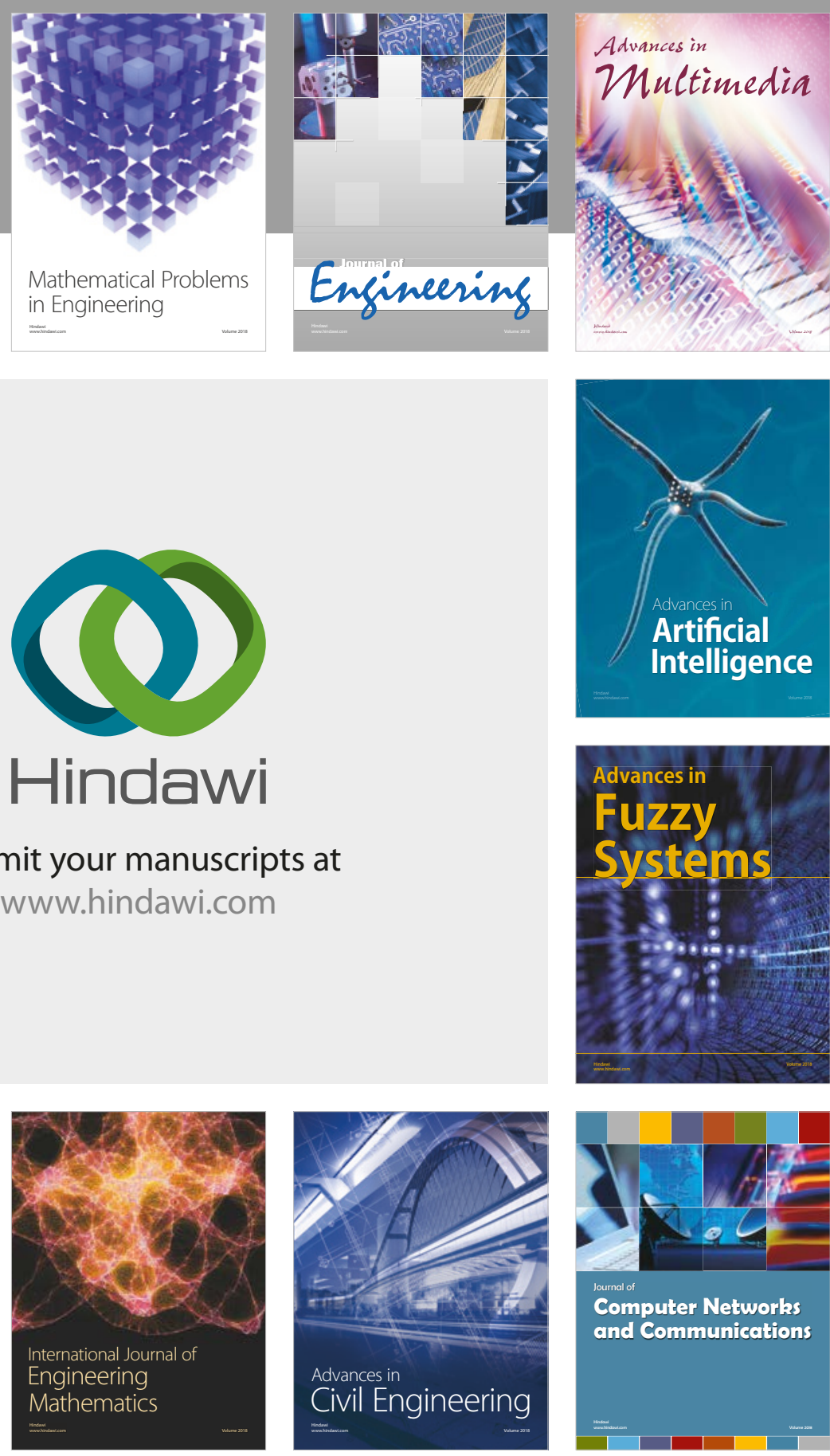

Computer Networks and Communications

Multimedia
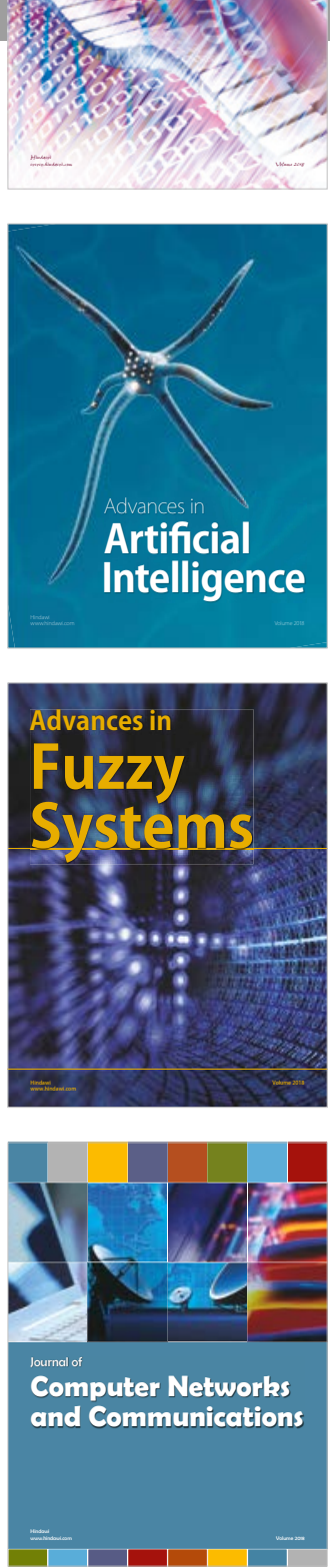

Advances in

Modelling \&

Simulation

in Engineering

interaction

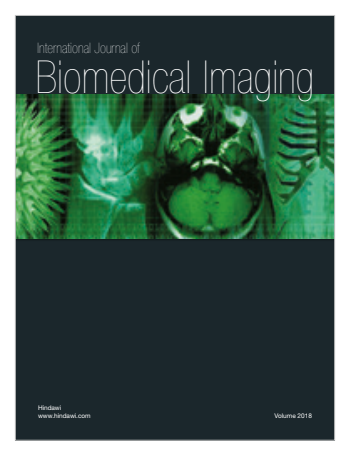

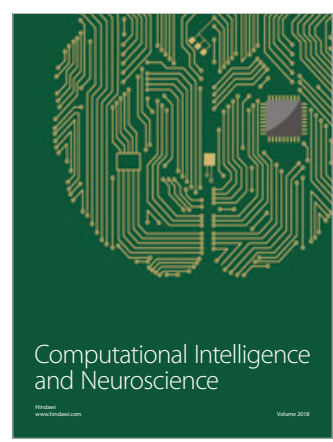

